Costa, N.M.C.; D’Arrichella, M.L.G.; Souza, M.A.; Costa, S.S.; Safadi, T.M. O (des)uso público em Unidades de Conservação: avaliação em algumas áreas protegidas do Estado do Rio de Janeiro. Anais do VIII Congresso Nacional de Ecoturismo e do IV Encontro Interdisciplinar de Ecoturismo em Unidades de Conservação. Revista Brasileira de Ecoturismo, São Paulo, v.4, n.4, 2011, p. 496.

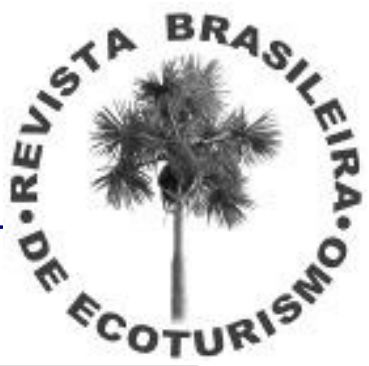

\title{
O (DES) USO PÚBLICO EM UNIDADES DE CONSERVAÇÃO: AVALIAÇÃO EM ALGUMAS ÁREAS PROTEGIDAS DO ESTADO DO RIO DE JANEIRO
}

\section{Nadja Maria Castilho da Costa*, Marcio Luiz Gonçalves D’Arrochella*, Maria} Aparecida de Souza*, Sheila Silva da Costa*, Thiago Moreira Safadi*

\section{*Universidade do Estado do Rio de Janeiro}

E-mails: nadjacastilho@oi.com.br,marciogeouerj@yahoo.com.br, mariaaparecidade.souza@gmail.com, sheilasc21@hotmail.com, thiagosafadi@gmail.com

Uma das funções de algumas unidades de conservação de proteção integral é permitir e monitorar a visitação e o lazer nas áreas destinadas ao uso público. Alguns parques fluminenses vêm promovendo práticas variadas utilizando, indiretamente, os recursos físico-bióticos neles existentes. Entretanto, poucos o fazem de maneira correta, acarretando impactos ao meio ambiente e, ao mesmo tempo, a insatisfação do visitante/turista. Neste contexto, o objetivo do presente trabalho é avaliar, comparativamente, o processo de planejamento e implementação do uso público em quatro unidades de conservação do Estado do Rio de Janeiro sendo três, localizadas na Região Metropolitana do Rio de Janeiro (Parque Nacional da Tijuca, Parque Estadual da Pedra Branca e Parque Natural Municipal da Taquara) e uma localizada no município de Rio das Ostras (Parque Natural Municipal dos Pássaros). A análise geral dos resultados obtidos mostra que, embora pertençam a mesma categoria de manejo (parque), existem diferenças significativas entre as quatro áreas protegidas, no que diz respeito ao tema analisado. As unidades que possuem plano de manejo, com programa de uso público definido, possuem estratégias de ação para a correta condução da visitação, embora em alguns casos não a efetue de maneira plenamente satisfatória, ao contrário das unidades desprovidas daquele documento básico, norteador do manejo e gestão de toda a área legalmente protegida. Nas unidades sem plano, as práticas ditas ecoturísticas são realizadas aleatoriamente, promovidas por agentes externos à administração da unidade, sem o devido acompanhamento do que está sendo efetivamente realizado.

Palavras-chave: Unidade de Conservação; Uso Público; Manejo. 